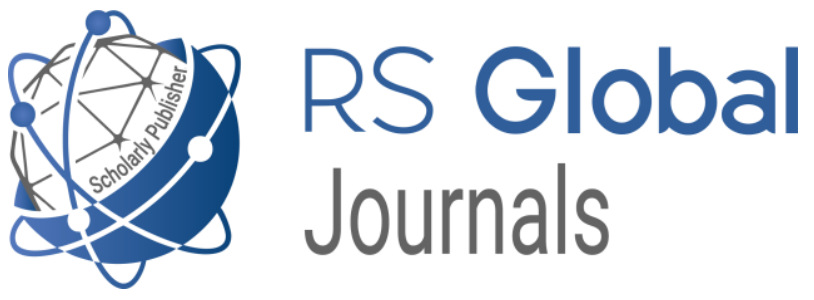

Scholarly Publisher

RS Global Sp. z O.O.

ISNI: 0000000484952390

Dolna 17, Warsaw, Poland 00-773

Tel: +48226022703

Email: editorial_office@rsglobal.pl

JOURNAL International Journal of Innovative Technologies in Social Science

p-ISSN

$2544-9338$

e-ISSN

2544-9435

PUBLISHER

RS Global Sp. z O.O., Poland

ARTICLE TITLE

ОБЛАСТИ КОМПЕТЕНЦИЙ ДИДАКТИЧЕСКИХ КАДРОВ: КОНСТАТИРУЮЩИЙ ЭТАП

$\operatorname{AUTHOR}(\mathbf{S})$

Афанас Алёна

Afanas Aliona. (2021) Teachers' Competence Areas:

ARTICLE INFO

Constitutional Stage. International Journal of Innovative

Technologies in Social Science. 2(30). doi:

10.31435/rsglobal_ijitss/30062021/7570

DOI

https://doi.org/10.31435/rsglobal_ijitss/30062021/7570

RECEIVED

29 April 2021

ACCEPTED

04 June 2021

PUBLISHED

08 June 2021

(c) (i)

LICENSE

This work is licensed under a Creative Commons Attribution

4.0 International License.

(C) The author(s) 2021. This publication is an open access article. 


\title{
ОБЛАСТИ КОМПЕТЕНЦИЙ ДИДАКТИЧЕСКИХ КАДРОВ: КОНСТАТИРУЮЩИЙ ЭТАП
}

\author{
Афанас Алёна, доктор педагогики (канд.пед.наук), конференциар (доиент), Институт \\ педагогических наук, Кишинев, Республика Молдова, \\ ORCID ID: https://orcid.org/0000-0001-6369-0940
}

DOI: https://doi.org/10.31435/rsglobal_ijitss/30062021/7570

\section{ARTICLE INFO}

Received 29 April 2021

Accepted 04 June 2021

Published 08 June 2021

\section{KEYWORDS}

competence, teacher, constitutive pedagogical experiment, pedagogical function, educational finality, research methods, tools.

\begin{abstract}
The article addresses the issue of teachers' competence areas, identified during the constitutive pedagogical experiment. The scientific analysis of the competence concept targeted towards the elaboration of the operational framework of professional development competencies, implemented within the constitutive pedagogical experiment. Also, the experimental data contributed to the identification of the areas of teachers' competence at the level of the education system and process. The constitutive experiment involved 888 subjects divided into two samples: the training sample and the control sample. The article presents each competence area results obtained within the two samples: training and control ones. The evaluation of the competence areas was performed based on the evaluation criteria established for the competencies such as managerial; relational; design and planning, specialized cognitive; teaching-learning; evaluation and monitoring. During the experiment, several research methods were used, such as theoretical, empirical and interpretive methods. The identification of the competence areas was made by applying a questionnaire addressed to teachers during the continuous professional training courses.
\end{abstract}

Citation: Afanas Aliona. (2021) Teachers' Competence Areas: Constitutional Stage. International Journal of Innovative Technologies in Social Science. 2(30). doi: 10.31435/rsglobal_ijitss/30062021/7570

Copyright: (C) 2021 Afanas Aliona. This is an open-access article distributed under the terms of the Creative Commons Attribution License (CC BY). The use, distribution or reproduction in other forums is permitted, provided the original author(s) or licensor are credited and that the original publication in this journal is cited, in accordance with accepted academic practice. No use, distribution or reproduction is permitted which does not comply with these terms.

Введение. Документы образовательной политики, например «Стандарты профессиональной компетентности дидактических кадров общего образования» направлены на оценку профессиональных компетенций учителя. В рамках стандартов профессиональной компетентности выделяются пять областей, которые охватывают деятельность дидактических кадров: проектирование дидактической деятельности, учебная среда, учебный процесс, профессиональное развитие и образовательное партнерство [17]. Таким образом, оценка деятельности учителя проводится по некоторым критериям и показателям эффективности, изложенным в этом документе. Все виды компетенций проанализированы в свете данного документа.

Программы повышения квалификации учителей в контексте реформ куррикулума включают несколько этапов:

- планирование непрерывного профессионального образования;

- организация непрерывного профессионального образования;

- мониторинг / координация достижений;

- оценка программы непрерывного профессионального образования;

- совершенствование программы непрерывного профессионального образования.

Обсуждая основные аспекты целей непрерывного профессионального образования (НПО), мы синтезировали несколько педагогических функций образовательных целей [5; 18]:

1) функиия проектирование обучения / повышения квалификации на системном уровне (разработка образовательной политики); на уровне процесса - в широком смысле: разработка образовательных стандартов, учебных планов, учебных программ; на уровне процесса - в узком 
смысле: календарное планирование учебных единиц или тем обучения, дидактические планирование учебной деятельности в рамках курсов повышения квалификации;

2) функция регулирования подразумевает получение обратной связи в конце курсов повышения квалификации, что позволяет улучшить их деятельность;

3) функция оценивания и самооценки, благодаря которой цели и компетенции становятся ориентирами эффективности образовательного процесса; качество целей, ясность изложения и их конкретизация являются важными условиями для подтверждения и достоверности оценки результатов курсов повышения квалификации; оценка на базе компетенций и в соответствии с образовательными стандартами - это новая парадигма оценки слушателей по окончании курсов повышения квалификации;

4) функция ценностной ориентации - она нужна, чтобы определить смысл и направления образовательного процесса; повышение профессиональной квалификации - это стремление, которое ориентировано на профессиональное и личностное развитие учителей;

5) функция организации и саморегулирования дидактических процессов подразумевается участие в дидактических процессах, включающих обучение и учение, в проектировании, разработке и оценке курсов повышения квалификации, что играет значительную роль при оценивании и саморегулировании формирующей деятельности;

6) функиия прогнозирования, предугадывания результатов курсов повышения квалификации посредством разработки конкретных достижимых и замеряемых образовательных целей; любая цель предвосхищает реальность, которой еще не существует;

7) диагностическая функция - итоговое и промежуточное оценивание определяют уровень сформированности конкретных компетенций в рамках курса / модуля, трансдисциплинарных компетенций и ключевых компетенций, сформированных в рамках курсов повышения квалификации.

Материалы и методы. Для проведения исследования и в контексте упомянутых эпистемологических ориентиров были применены следующие методы:

- теоретические - научная документация, анализ педагогических явлений и нормативных документов (документальный анализ), синтез, дедукция, корреляция, обобщение, систематизация, сравнение и теоретическое моделирование;

- эмпирические - педагогический эксперимент, сбор данных с помощью анкет (анкетирование, опрос, интервью), обработка экспериментальных данных;

- интерпретативные - метод систематического наблюдения, количественный и качественный анализ данных, анализ продуктов деятельности учителя в ходе курсов повышения квалификации.

Теоретическая база исследования. Проблема эволюции концепта компетенция на международном уровне рассматривается многими авторами: A. Bron [2], Ph. Jonnaert [13], N. Chomsky [apud 12], J. De Vito [apud 12], F. M. Jablin [12], L. Putnam [12], X. Roegiers [15], M. Ionescu [apud 4], L. Ciolan [4], A. Stoica [apud 4], R. Mihail [apud 4], L. Şoitu [19], I. O. Pânișoară [14], L. Iacob [10], А. Н. Леонтьев [20], А. Ю. Сергиенко [21]; на наџиональном уровне: Vl. Guțu [8], T. Callo [3], Goraș-Postică V. [6], Gremalschi A. [7], M. Hadârcă [9], Ș. Isac [11], L. Sadovei [16] и др. Профессиональные компетенции, отраженные в программах непрерывного профессионального образования, рассматриваются как результат сформированных компетенций у учителей в рамках курсов повышения квалификации. На базе вышеизложенного мы выделяем различные компетенции, среди которых: компетенции на уровне знаний и понимания, направленные на выявление, объяснение, интерпретацию, комментирование и экстраполяцию фактов, событий и т. д. в повседневном аутентичном контексте и направлены на отображение, признание фактических данных, определений, критериев, методов, правил, принципов, теорий и т. д.

Компетенции на уровне применения, которые направлены на использование полученной информации для объяснения и / или решения новых, неизвестных проблем.

Компетенции на уровне интеграџии направлены на обобщение, перенос, адаптацию к новым контекстам; индивидуальное и групповое исследование проблемных ситуаций.

Компетенцию можно рассматривать с трех сторон: инструмент качества и достижения в профессиональной деятельности, цель куррикулума курсов повышения квалификации и их результат. В программе курсов повышения квалификации и на занятиях по повышению квалификации представлена парадигма компетенций, поскольку компетенции являются 
интегрированным явлением и состоят из следующих компонентов: знания, умения и навыки, ценностные отношения, они рассматриваются с прикладной и прагматической точки зрения как для настоящего момента, так и для дальнейшего развития профессиональной деятельности.

Результаты исследования и обсуждений. Профессиональные компетенции складываются из специфических компетенций, сформированных у дидактических кадров благодаря курсам / единицам курса / модулям и единиц компетенций. В рамках анализа компетенций мы разработали операциональную структуру развития профессиональных компетенций (РПК) для учителей (таблица 1).

Таблица 1. Операциональная структура компетенций профессионального развития

\begin{tabular}{|c|c|c|}
\hline $\begin{array}{c}\text { Типы } \\
\text { компетенций }\end{array}$ & Таксономия знаний & $\begin{array}{c}\text { Специфические компетенции для } \\
\text { курсов/раздела курсов/модуля/концепта }\end{array}$ \\
\hline 1 & 2 & 3 \\
\hline $\begin{array}{l}\text { На уровне } \\
\text { знаний и } \\
\text { интеграции }\end{array}$ & $\begin{array}{l}\text { - фактические знания: знание } \\
\text { терминологии, понятий, } \\
\text { явлений, процессов, } \\
\text { взаимоотношений и т.д.; } \\
\text { - концептуальные знания: } \\
\text { знание классификаций и } \\
\text { категорий, знание принципов, } \\
\text { обобщений, знание теорий, } \\
\text { моделей и структур }\end{array}$ & $\begin{array}{l}\text { - выявление понятий, явлений, процессов, } \\
\text { взаимоотношений; } \\
\text { - определяющие понятия; } \\
\text { - наблюдение за некоторыми явлениями; } \\
\text { - перечисление фактов, явлений, процессов и т.д. } \\
\text { - воспроизведение определений, текстов и т.д.; } \\
\text { - сбор данных, информации и т.д.; } \\
\text { - описание фактов, явлений, процессов и т.д.; } \\
\text { - выделение фактов, явлений, процессов и т.д. } \\
\text { - анализ и синтез; } \\
\text { - сравнение и различение; } \\
\text { - установление отношений; } \\
\text { - категоризация и } \\
\text { - классификация и т.д. }\end{array}$ \\
\hline $\begin{array}{l}\text { На уровне } \\
\text { применения }\end{array}$ & $\begin{array}{l}\text { - процедурные знания: знание } \\
\text { специфических алгоритмов } \\
\text { предмета; знание приемов и } \\
\text { методов, специфичных для } \\
\text { предмета; } \\
\text { знание критериев для } \\
\text { реализации различных целей, } \\
\text { связанных с решением } \\
\text { проблем, проблемных } \\
\text { ситуаций; } \\
\text { знание конкретного контекста } \\
\text { проблемы; } \\
\text { знание конкретного контекста } \\
\text { проблемы; } \\
\text { знание стратегий для решения } \\
\text { проблем }\end{array}$ & $\begin{array}{l}\text { - изучение; } \\
\text { - исследование; } \\
\text { - экспериментирование; } \\
\text { - решение простых } \\
\text { - примеров; } \\
\text { - создание схем, моделей; } \\
\text { - применение схем, моделей; алгоритмов; } \\
\text { - решение проблем посредством моделирования } \\
\text { и алгоритмизации; проведение тематических } \\
\text { исследований, проблемных ситуаций; } \\
\text { - ожидание результатов; } \\
\text { - представление данных; } \\
\text { - структурирование; } \\
\text { - моделирование; } \\
\text { - транспонирование, описание процессов, } \\
\text { явлений, систем; } \\
\text { - генерация идей, концепций, решений; } \\
\text { - аргументированные высказывания; } \\
\text { демонстрация; } \\
\text { - интерпретация; } \\
\text { - иллюстрация; } \\
\text { - составление отчетов; } \\
\text { - обьяснение и т. д. }\end{array}$ \\
\hline
\end{tabular}


Продолжение таблицы 1.

\begin{tabular}{|c|c|c|}
\hline 1 & 2 & 3 \\
\hline $\begin{array}{l}\text { На уровне } \\
\text { интеграции }\end{array}$ & $\begin{array}{l}\text { - стратегические знания: } \\
\text { передача / применение знаний в } \\
\text { других ситуациях, контекстах, } \\
\text { сферах деятельности; } \\
\text { уровень реализации связей } \\
\text { между результатами, } \\
\text { контекстами, сферами } \\
\text { профессиональной } \\
\text { деятельности; } \\
\text { планирование / разработка } \\
\text { новых действий; } \\
\text { самостоятельность обучаемого } \\
\text { при разработке проекта }\end{array}$ & $\begin{array}{l}\text { - заключение; } \\
\text { - оценка результатов; } \\
\text { - системный анализ } \\
\text { - некоторых данных, явлений, процессов; } \\
\text { - разработка стратегии; } \\
\text { - взаимосвязь между разными типами } \\
\text { представлений; } \\
\text { - создание новых идей; } \\
\text { - экстраполяция; } \\
\text { - расширение; } \\
\text { - абстракция; } \\
\text { - признание; } \\
\text { - реализация; } \\
\text { - обобщение и конкретизация } \\
\text { - оптимизация; } \\
\text { - транспонирование; } \\
\text { - перевод; } \\
\text { - адаптация и адекватность контексту; } \\
\text { - управление; } \\
\text { - планирование / проектирование; } \\
\text { - индивидуальные и групповые исследования; } \\
\text { - концептуализация; } \\
\text { - принятие решения; } \\
\text { - эффективное обшение и т. л. }\end{array}$ \\
\hline
\end{tabular}

В рамках исследования были установлены цель и задачи педагогического констатирующего эксперимента.

Целью констатирующего эксперимента было определение исходного уровня профессиональной подготовки дидактических кадров общего образования по областям компетенций.

Задачи констатирующего эксперимента:

- определение областей компетенций учителей путем формулирования различных вопросов, направленных на эти области;

- определение уровня сформированности профессиональных компетенций учителей общего образования.

Анализ теоретических исследований позволил установить следующие основные области компетенций учителей:

- Реляционная компетенция: развитие конструктивных отношений, основанных на справедливости;

- Компетенция преподавания и обучения: использование возможностей учебного, внеклассного и внешкольного обучения;

- Менеджерская компетенция: планирование, организация, реализация и мониторинг образовательных и нормативных документов;

- Компетенция в области проектирования и планирования: формулирование целей обучения по преподаваемому предмету, а также внеучебной и внешкольной деятельности;

- Специализированная когнитивная компетенция: разработка, планирование $u$ внедрение в учебный прочесс куррикулума;

- Компетенция оценки и мониторинга: установление конкретных критериев оценки, используемых в рамках преподаваемой дисциплины / запланированных видов деятельности, и их реализачия в учебном процессе [1].

В рамках педагогического эксперимента было применено несколько инструментов для диагностики ситуации в сфере непрерывного профессионального образования на уровне 
образовательной системы и процесса. Прикладные анкеты сфокусированы на областях компетенций учителей: менеджерская компетенция, реляционная компетенция, компетенция проектирования и планирования, специализированная когнитивная компетенция, компетенция преподаванияобучения, компетенция оценки и мониторинга. В ходе констатирующего эксперимента испытуемых спрашивали, какие компетенции развиваются в профессиональной деятельности в образовательном учреждении. На основе анализа представленных ответов мы сделали вывод о следующих результатах, полученных в двух выборках: выборка обучающихся (EF, 441 субъектов) и контрольная выборка (EM, 447 субъектов) для каждой компетенции (таблицы 2. - 7.):

Таблица 2. Реляционная компетенция (констатация)

Критерии оценивания/ Реляционная компетенция

развитие конструктивных отношений с учащимися на основе справедливости, уважения, доверия и поддержки продвижение позитивных ценностей, отношений и поведения по отношению к ученикам создание благоприятного климата для обучения

признание, оценка и использование социального, религиозного, этнического и языкового разнообразия класса во благо учащихся предоставление практических советов коллегам по вопросам равенства, инклюзивности и разнообразия для удовлетворения потребностей учащихся

В результате анализа экспериментальных данных по реляционной компетенции мы выяснили, что отобранные для исследования выборки в целом однородны, а уровень обучающихся сходен с уровнем контрольной группы.

Таблица 3. Компетенция преподавания и обучения (констатация)

\begin{tabular}{|c|c|c|}
\hline $\begin{array}{c}\text { Критерии оценивания/ Компетенция } \\
\text { преподавания и обучения }\end{array}$ & $\begin{array}{c}\text { Выборка обучающихся } \\
\text { (ЕF) (441 субъектов) / } \\
\text { уровень }\end{array}$ & $\begin{array}{c}\text { Контрольная выборка } \\
\text { (EM) (447 субъектов) } / \\
\text { уровень }\end{array}$ \\
\hline $\begin{array}{l}\text { выявление и использование возможностей учебного, } \\
\text { внеклассного и внешкольного обучения }\end{array}$ & $\begin{array}{c}\text { 43,08\% (190 субъектов) } \\
\text { (низкий) }\end{array}$ & $\begin{array}{c}\text { 43,40\% (194 субъектов) } \\
\text { (низкий) }\end{array}$ \\
\hline $\begin{array}{l}\text { рефлексия об эффективности собственной } \\
\text { педагогической деятельности и анализ ее влияния на } \\
\text { успеваемость и результаты учащихся }\end{array}$ & $\begin{array}{c}51,02 \% \text { (225 субъектов) } \\
\text { (хороиий) }\end{array}$ & $\begin{array}{l}\text { 50,78\% (227 субъектов) } \\
\text { (хорошийо) }\end{array}$ \\
\hline $\begin{array}{l}\text { регулярное совершенствование подходов, } \\
\text { используемых в учебной деятельности, а также при } \\
\text { необходимости }\end{array}$ & $\begin{array}{c}\text { 38,54\% (170 субъектов) } \\
\text { (низкий) }\end{array}$ & $\begin{array}{l}\text { 37,58\% (168 субъектов) } \\
\text { (низкий) }\end{array}$ \\
\hline $\begin{array}{l}\text { регулярное совершенствование подходов, } \\
\text { используемых в учебной деятельности, а также при } \\
\text { необходимости }\end{array}$ & $\begin{array}{c}38,54 \% \text { (170 субъектов) } \\
\text { (низкий) }\end{array}$ & $\begin{array}{l}\text { 37,58\% (168 субъектов) } \\
\text { (низкий) }\end{array}$ \\
\hline $\begin{array}{l}\text { анализ влияния обратной связи на учащихся и } \\
\text { помощь учащимся в улучшении успеваемости в } \\
\text { школе }\end{array}$ & $\begin{array}{l}51,47 \% \text { (227 субъектов) } \\
\text { (хороший) }\end{array}$ & $\begin{array}{l}\text { 50,33\% (225 субъектов) } \\
\text { (хороший) }\end{array}$ \\
\hline $\begin{array}{l}\text { знание, понимание, использование и оценка } \\
\text { широкого спектра методик преподавания и обучения, } \\
\text { разнообразного содержания образовательной } \\
\text { деятельности для повышения интереса учащихся }\end{array}$ & $\begin{array}{l}56,91 \% \text { (251 субъектов) } \\
\text { (хороший) }\end{array}$ & $\begin{array}{c}56,59 \% \text { (253 субъектов) } \\
\text { (хороший) }\end{array}$ \\
\hline $\begin{array}{l}\text { предоставление учащимся положительных и } \\
\text { конструктивных отзывов для улучшения их учебного } \\
\text { опыта }\end{array}$ & $\begin{array}{c}\text { 36,28\% (160 субъектов) } \\
\text { (низкий) }\end{array}$ & $\begin{array}{c}\text { 36,68\% (164 субъектов) } \\
\text { (низкий) }\end{array}$ \\
\hline эффективное информирование о целях урока & $\begin{array}{c}\text { 19,27\% (85 субъектов) } \\
\text { (неудовлетвори- } \\
\text { тельный) }\end{array}$ & $\begin{array}{c}\text { 19,46\% (87 субъектов) } \\
\text { (неудовлетвори- } \\
\text { тельный })\end{array}$ \\
\hline
\end{tabular}


В результате анализа данных о преподавательско-образовательной компетенции мы выяснили, что отобранные для исследования выборки в целом однородны, а уровень обучающихся сходен с уровнем контрольной группы. Существует незначительная разница в критерии анализа влияния обратной связи на учащихся, и указания учащимся, как улучшить свою школьную успеваемость, в ЕF - хороший уровень 51,47\% (227 субъектов), а в ЕМ - низкий уровень 50,33\% (225 субъектов) в соответствии с уровнями успеваемости, установленными в нашем исследовании.

Таблица 4. Менеджерская компетенция (констатация)

\begin{tabular}{|c|c|c|}
\hline $\begin{array}{c}\text { Критерии оценивания/ } \\
\text { Менеджерская компетенция }\end{array}$ & $\begin{array}{c}\text { Выборка обучающихся } \\
\text { (EF) (441 субъектов) / } \\
\text { уровень } \\
\end{array}$ & $\begin{array}{c}\text { Контрольная выборка } \\
\text { (ЕМ) (447 субъектов) / } \\
\text { уровень } \\
\end{array}$ \\
\hline $\begin{array}{l}\text { мотивация учащихся максимально } \\
\text { активизировать свои учебные усилия и } \\
\text { достичь самых высоких результатов }\end{array}$ & $\begin{array}{c}81,63 \% \text { (360 субъектов) } \\
\text { (очень хороший) }\end{array}$ & $\begin{array}{l}80,98 \% \text { (362 субъекта) } \\
\text { (очень хороиий) }\end{array}$ \\
\hline $\begin{array}{l}\text { установление и поддержание } \\
\text { эффективного контроля над классом, их } \\
\text { деятельностью и поведением отдельных } \\
\text { групп учащихся }\end{array}$ & $\begin{array}{c}\text { 39,68\% }(175 \text { субъектов) } \\
\text { (низкий) }\end{array}$ & $\begin{array}{c}\text { 38,03\% (170 субъектов) } \\
\text { (низкий) }\end{array}$ \\
\hline $\begin{array}{l}\text { справедливое и равное отношение к } \\
\text { учащимся }\end{array}$ & $\begin{array}{l}81,17 \% \text { (358 субъектов) } \\
\text { (очень хороший) }\end{array}$ & $\begin{array}{l}80,53 \% \text { (360 субъектов) } \\
\text { (очень хорочий) }\end{array}$ \\
\hline $\begin{array}{l}\text { эффективное сообщение о любых } \\
\text { проблемах, связанных с физическим } \\
\text { пространством школы (ремонт, починка и } \\
\text { т.д.) }\end{array}$ & $\begin{array}{c}\text { 13,60\% (60 субъектов) } \\
\text { (неудовлетворительный) }\end{array}$ & $\begin{array}{c}\text { 14,31\% (64 субъекта) } \\
\text { (неудовлетворительный) }\end{array}$ \\
\hline $\begin{array}{l}\text { управление кризисными ситуациями в } \\
\text { классе }\end{array}$ & $\begin{array}{c}\text { 27,89\% (123 субъекта) } \\
\text { (низкий) }\end{array}$ & $\begin{array}{c}28,41 \% \text { (127 субъектов) } \\
\text { (низкий) }\end{array}$ \\
\hline $\begin{array}{l}\text { продвижение и поощрение } \\
\text { сотрудничества, совместной работы в } \\
\text { классе и совместного обучения }\end{array}$ & $\begin{array}{c}50,11 \% \text { (221 субъект) } \\
\text { (низкий) }\end{array}$ & $\begin{array}{c}\text { 50,11\% (224 субъекта) } \\
\text { (низкий) }\end{array}$ \\
\hline
\end{tabular}

В результате анализа данных о менеджерской компетентности мы выяснили, что отобранные для исследования выборки в целом однородны, а уровень обучающихся сходен с уровнем контрольной группы.

Таблица 5. Компетенция в области проектирования и планирования (констатация)

\begin{tabular}{|c|c|c|}
\hline $\begin{array}{c}\text { Критерии оценивания/ Компетенция в } \\
\text { области проектирования и планирования }\end{array}$ & $\begin{array}{c}\text { Выборка } \\
\text { обучающихя (EF) } \\
(441 \text { субъектов) / } \\
\text { уровень } \\
\end{array}$ & $\begin{array}{c}\text { Контрольная выборка } \\
\text { (ЕМ) (447 субьектов) / } \\
\text { уровень }\end{array}$ \\
\hline $\begin{array}{l}\text { демонстрация полного знания целей } \\
\text { обучения на предстоящий год }\end{array}$ & $\begin{array}{c}29,47 \% \text { (130 субъектов) } \\
\text { (низкий) }\end{array}$ & $\begin{array}{c}\text { 30,42\% (136 субъектов) } \\
\text { (низкий) }\end{array}$ \\
\hline $\begin{array}{l}\text { знание об изменениях в куррикулуме и их } \\
\text { формулировки в устной и письменной } \\
\text { форме }\end{array}$ & $\begin{array}{c}\text { 32,65\% (144 субъектов) } \\
\text { (низкий) }\end{array}$ & $\begin{array}{c}\text { 32,66\% (146 субъектов) } \\
\text { (низкий) }\end{array}$ \\
\hline $\begin{array}{l}\text { предоставление учащимся возможностей } \\
\text { для развития их мышления и навыков } \\
\text { обучения }\end{array}$ & $\begin{array}{l}\text { 77,32\% (341 субъектов) } \\
\text { (очень хороиий) }\end{array}$ & $\begin{array}{l}77,18 \% \text { (345 субъектов) } \\
\text { (очень хороиий) }\end{array}$ \\
\hline $\begin{array}{l}\text { использование подходов и учебных } \\
\text { ресурсов, которые тесно связаны с целями } \\
\text { обучения и оказывают значительное } \\
\text { влияние на успеваемость учащихся }\end{array}$ & $\begin{array}{c}55,55 \% \text { (245 субъектов) } \\
\text { (хороший) }\end{array}$ & $\begin{array}{c}\text { 55,92\% (250 субъектов) } \\
\text { (хороший) }\end{array}$ \\
\hline
\end{tabular}

В результате анализа данных о компетенция в области проектирования и планирования мы выяснили, что отобранные для исследования выборки в целом однородны, а уровень обучающихся сходен с уровнем контрольной группы. 
Таблица 6. Специализированная когнитивная компетенция (констатация)

\begin{tabular}{|c|c|c|}
\hline $\begin{array}{c}\text { Критерии оценивания/ } \\
\text { Специализированная когнитивная } \\
\text { компетенция }\end{array}$ & $\begin{array}{c}\text { Выборка обучающихся } \\
\text { (ЕF) (441 субъектов) / } \\
\text { уровень }\end{array}$ & $\begin{array}{c}\text { Контрольная выборка } \\
\text { (ЕМ) (447 субъектов) / } \\
\text { уровень }\end{array}$ \\
\hline $\begin{array}{l}\text { наличие специальных знаний по разработке, } \\
\text { планированию и реализации куррикулума }\end{array}$ & $\begin{array}{c}\text { 68,02\% (300 субъектов) } \\
\text { (хороший) }\end{array}$ & $\begin{array}{c}\text { 67,56\% (302 субъекта) } \\
\text { (хороший) }\end{array}$ \\
\hline $\begin{array}{l}\text { приложенные усилия, чтобы быть в курсе } \\
\text { последних событий в области преподавания } \\
\text { дисциплины }\end{array}$ & $\begin{array}{c}58,95 \% \text { (260 субъектов) } \\
\text { (хороший) }\end{array}$ & $\begin{array}{c}\text { 59,06\% (264 субъекта) } \\
\text { (хороший) }\end{array}$ \\
\hline $\begin{array}{l}\text { консультации по специализированным } \\
\text { материалам, сотрудничество и деятельность в } \\
\text { профессиональных организациях }\end{array}$ & $\begin{array}{c}51,47 \% \text { (227 субъектов) } \\
\text { (хороший) }\end{array}$ & $\begin{array}{c}51,45 \% \text { (230 субъектов) } \\
\text { (хороший) }\end{array}$ \\
\hline $\begin{array}{l}\text { знание и понимание вклада преподаваемой } \\
\text { дисциплины в междисциплинарную и } \\
\text { трансдисциплинарную учебную деятельность }\end{array}$ & $\begin{array}{c}56,68 \% \text { (250 субъектов) } \\
\text { (хороиий) }\end{array}$ & $\begin{array}{c}55,92 \% \text { (250 субъектов) } \\
\text { (хороший) }\end{array}$ \\
\hline $\begin{array}{l}\text { изучение широкого спектра источников } \\
\text { информации о последних разработках в } \\
\text { данной области и представление этой } \\
\text { информации в понятной и подходящей форме }\end{array}$ & $\begin{array}{c}\text { 44,67\% (197 субъектов) } \\
\text { (низкий) }\end{array}$ & $\begin{array}{c}43,62 \% \text { (195 субъектов) } \\
\text { (низкий) }\end{array}$ \\
\hline
\end{tabular}

В результате анализа данных о специализированной когнитивной компетенции мы выяснили, что отобранные для исследования выборки в целом однородны, а уровень обучающихся сходен с уровнем контрольной группы.

Таблица 7. Компетенция оценки и мониторинга (констатация)

\begin{tabular}{|c|c|c|}
\hline $\begin{array}{c}\text { Критерии оценивания/ Компетенция } \\
\text { оценки и мониторинга }\end{array}$ & $\begin{array}{c}\text { Выборка обучающихся } \\
\text { (ЕF) (441 субъектов) / } \\
\text { уровень }\end{array}$ & $\begin{array}{c}\text { Контрольная выборка } \\
\text { (ЕМ) (447 субъектов) } / \\
\text { уровень }\end{array}$ \\
\hline $\begin{array}{l}\text { знание конкретных критериев оценки, } \\
\text { используемых в изучаемом предмете }\end{array}$ & $\begin{array}{l}58,95 \% \text { (260 субъектов) } \\
\text { (хороший) }\end{array}$ & $\begin{array}{c}\text { 53,69\% (240 субъектов) } \\
\text { (хороший) }\end{array}$ \\
\hline $\begin{array}{l}\text { выбор подходящего инструмента оценки для } \\
\text { проверки компетенций учащихся }\end{array}$ & $\begin{array}{c}65,75 \% \text { (290 субъектов) } \\
\text { (хороший) }\end{array}$ & $\begin{array}{c}\text { 62,63\% (280 субъектов) } \\
\text { (хороший) }\end{array}$ \\
\hline $\begin{array}{l}\text { проведение оценочной деятельности и } \\
\text { интерпретация результатов учащихся }\end{array}$ & $\begin{array}{c}50,34 \% \text { (222 субъекта) } \\
\text { (низкий) }\end{array}$ & $\begin{array}{c}46,97 \% \text { (210 субъектов) } \\
\text { (низкий) }\end{array}$ \\
\hline $\begin{array}{l}\text { предоставление учащимся конструктивных и } \\
\text { положительных отзывов, чтобы мотивировать } \\
\text { их к обучению }\end{array}$ & $\begin{array}{c}53,74 \% \text { (237 субъектов) } \\
\text { (хороший) }\end{array}$ & $\begin{array}{l}51,45 \% \text { ( }(230 \text { субъъектов) } \\
\text { (хороший) }\end{array}$ \\
\hline $\begin{array}{l}\text { получение и принятие отзывов о собственной } \\
\text { педагогической деятельности }\end{array}$ & $\begin{array}{c}37,41 \% \text { (165 субъектов) } \\
\text { (низкий) }\end{array}$ & $\begin{array}{c}\text { 35,79\% (160 субъектов) } \\
\text { (низкий) }\end{array}$ \\
\hline $\begin{array}{l}\text { повышение эффективности оценки класса } \\
\text { учителями }\end{array}$ & $\begin{array}{c}29,25 \% \text { (129 субъектов) } \\
\text { (низкий) }\end{array}$ & $\begin{array}{c}27,96 \% \text { (125 суббектов) } \\
\text { (низкий) }\end{array}$ \\
\hline
\end{tabular}

В результате анализа данных о компетенция оценки и мониторинга мы выяснили, что отобранные для исследования выборки в целом однородны, а уровень обучающихся сходен с уровнем контрольной группы.

Выводы. Анализ экспериментальных данных выявил необходимость в рамках курсов повышения квалификации уделять особое внимание учителей на основы областей компетенций, а не только на учебные дисциплины или куррикулум; была выявлена необходимость комплексного подхода к областям компетенций на уровне образовательной системы и процесса.

Анализ полученных данных должен быть учтен при разработке референциала для непрерывного профессионального образования с учетом компетенций дидактических кадров, который включает в себя следующие компоненты: условия непрерывного профессионального образования, программы повышения квалификации, планирование непрерывного профессионального обучения, конечные цели курсов повышения квалификации, методологию разработки куррикулума непрерывного профессионального обучения учителей; экспериментальную апробацию методики непрерывной профессиональной подготовки учителей общего образования. Программы для преподавателей, предназначенные для повышения квалификации учителей, продемонстрировали в ходе эксперимента значимые данные для обучающей выборки (EF) по сравнению с контрольной выборкой (MS). Инструменты исследования, используемые в педагогическом эксперименте, эффективны и пригодны для использования на курсах повышения квалификации. 


\section{ЛИТЕРАТУРА}

1. Afanas, A. Domenii de competențe ale cadrului didactic. În: Educația: factor primordial în dezvoltarea societății, Materialele Conferinţei Ştiinţifice Internaţionale, 2020, Chişinău: Institutul de Ştiinţe ale Educaţiei, 2020, p. 449 - 456. ISBN 978-9975-48-178-6.

2. Bron, A., Schemman, M. Social Science Theories in Adult Education Research, Bochum Studies in International Adult Education LIT Verlag, Munster, 2002. 338 p. ISBN 38258578759783825857875.

3. Callo, T. Pedagogia practică a atitudinilor. Chişinău: Editura Grupul Editorial Litera 2014. 240 p.ISBN 978-9975-74-340-2.

4. Ciolan, L. Învăţarea integrată. Fundamente pentru un curriculum transdisciplinar. Iaşi. Editura Polirom, 2008. 277 p. ISBN 9789734610341.

5. Cuznețov, L. Referențialul axiologic comun al educației formale, nonformale și informale. În: Educația integrală: fundamentări teoretico-paradigmatice și aplicative. Chișinău: Institutul de Științe ale Educației, 2015, 248 p. ISBN 978-9975-48-096-3. 91

6. Goraş-Postică, V. Schimb de experienţă şi bune practici privind educaţia finlandeză, centrată pe profesor şi pe elev. În: Revista Didactica Pro..., Revistă de teorie şi practică educaţională, 2018, nr. 2 (108), p. 9-13. ISSN 1810-6455.

7. Gremalschi, A. Formarea competenţelor-cheie în învăţământul general: provocări şi constrângeri. Studiu de politici educaţionale. Chișinău, 2015. 89 p. ISBN 978-9975-9609-8-4.

8. Guțu, V. Competenţa - abordare situaţională, structurală şi metodologică. În: Studia Universitatis (Seria Ştiinţe ale Educaţiei). 2018, nr. 5 (115), p. 3-12. ISSN 1857-2103.

9. Hadîrcă, M. Competența de comunicare: conceptualizare, formare, evaluare. Chișinău: IȘE, 2020. 165 p. ISBN 978-9975-48-177-9.

10. Iacob, L. Comunicarea în contextul educativ și didactic. În Revista Didactica Pro, Chișinău, 2004, nr. 2 (24), p. 34-40. ISSN 1810-6455.

11. Isac, Ș. Diagnosticarea pedagogică a nivelului de profesionalizare a cadrelor didactice. Chișinău: Editura Print-Caro, 2020, 93 p. ISBN 978-9975-48-180-9.

12. Jablin, F. M., Putnam, L. L. The New Handbook of Organizational Communication. Thousand Oaks: Sage Publications Inc., 2001. 820 p. ISBN 978-1-4129-1525-0.

13. Jonnaert Ph., Ettayebi M., Defise R. Curriculum şi competenţe: un cadru operaţional. Cluj-Napoca: Editura ASCR, 2010. 125 p. ISBN 978-973-7973-98-6.

14. Pânişoară, I. O. Profesorul de succes: 59 de principii de pedagogie practică. Ed. a II-a. Iaşi: Polirom, 2015. 245 p. ISBN 978-973-46-5277-8.

15. Roegiers, X. De la connaissance a la competence. Bruxelles: PIE Peter Lang, 2017. 301 p. ISBN-13: 9782807603226

16. Sadovei, L. Competenţa de comunicare didactică: repere teoretice şi metodologie. Chişinău: UPS „, Ion Creangă”, 2008. 172 p. ISBN 978-9975-46-026-2.

17. Standarde de competenţă profesională ale cadrelor didactice din învățământul general. Chişinău, 2018. Consiliul Național pentru Curriculum, proces-verbal nr. 18 din 03 iulie 2018; prin Ordinul ministrului educaţiei nr. 1124 din 20 iulie 2018. 9 p. www.mecc.gov.md. 207

18. Şerbănescu, L., Bocoş, M. - D., Ioja I. Managementul programelor de formare continuă a cadrelor didactice. Ghid practic. Iaşi: Editura Polirom, 2020, 278 p. 184

19. Şoitu, L. Pedagogia comunicării. Bucureşti: Editura Didactică şi Pedagogică, 1997. 273 p. ISBN 973-611-199-7.

20. Леонтьев, А. Н. Деятельность. Сознание. Личность. Москва: Смысл, Академия, 2005.352 с. (Классическая учебная книга). ISBN 5-89357-153-3, 5-7695-1624-0.

21. Сергиенко, А. Ю. Компаративный анализ профессиональных стандартов педагога в России и за рубежом, в Человек и закон № 4 (57), Санкт - Петербург, 2019, с. 184 - 191, ISSN 1815 - 7041. 